\title{
AVALIAÇÃO DO POTENCIAL FITOTÓXICO DE EXTRATOS E FRAÇÕES DE EPLINGIELLA FRUTICOSA SOBRE A GERMINAÇÃO DE CUCUMIS SATIVUS $l$.
}

\section{$\underline{\text { Marielly da Luz santos }}{ }^{1}$; Lenaldo Muniz de Oliveira $^{2}$; Táris Maria Macedo de Santana ${ }^{3}$}

1. Bolsista IC/FABESP, Graduanda em agronomia da Universidade Estadual de Feira de Santana, e-mail: Luzmarielly01@gmail.com

2.Orientador, Departamento de Ciências Biológicas, Universidade Estadual de Feira de Santana, e-mail: Lenaldo.uefs@gmail.com

3.Mestre em recursos genéticos vegetais,Universidade Estadual de Feira de Santana, e-mail:tarismaria@gmail.com.

PALAVRAS-CHAVE: Alelopatia; potencial fitotóxicos; germinação; aleloquimicos.

\section{INTRODUÇÃO}

As plantas podem interagir estimulando ou inibindo algumas situações no ecossistema. Muitas espécies sintetizam substâncias, denominados de metabolitos secundários, em que na maioria das vezes, podem apresentar efeitos alelopáticos. Alelopatia pode ser definida como a interferência positiva ou negativa de compostos do metabolismo secundário produzidos por uma planta (aleloquímicos), que podem apresentar efeitos positivos no desenvolvimento das plantas, ou negativos, sendo o seu entendimento um grande desafio.

A alelopatia é extremamente importante no sucesso de sistemas de cultivo agrícolas, tanto de ciclo curto ou perenes, sendo uma alternativa para a produção, controle e manejo de culturas. Mediante a isto, o presente trabalho teve como objetivo avaliar o potencial fitotóxico de extratos etanólicos e suas frações obtidos de folhas de Eplingiella fruticosa (Salzm. ex. Benth.) J.F.B. Pastore sobre a germinação e crescimento radicular de sementes de Cucumis sativum L.

\section{MATERIAL E MÉTODOS}

O experimento foi realizado no Laboratório de Germinação do Horto Florestal da UEFS, Feira de Santana, Bahia, localizada a $12^{\circ} 16^{\prime} 087^{\prime \prime S}$ e $38^{\circ} 56^{\prime} 346^{\prime \prime} \mathrm{W}$, a uma altitude de $243 \mathrm{~m}$.

Folhas de E. fruticosa foram coletadas no mês de abril, as $10 \mathrm{~h}$ da manhã, em plantas da espécie mantidas na Coleção de Plantas Medicinais e Aromáticas do Horto Florestal, e secas em prateleiras de secagem à temperatura ambiente até peso constante. As folhas foram trituradas em moinho de facas, pesando-se $500 \mathrm{~g}$ do material vegetal, no qual foi adicionado $1,5 \mathrm{~L}$ de etanol (92,3\%). O material foi sonicado em banheira de ultrassom (Ultronique, Modelo Q13/37A, Lote 101713, Frequência $37 \mathrm{kHz}$, Potencia $220 \mathrm{~W}$ pmax) por $60 \mathrm{~min}$ a $40^{\circ} \mathrm{C}$. Depois de filtrado, 
adicionou-se $800 \mathrm{~mL}$ de etanol e levou-se para ultrassom por mais $60 \mathrm{~min}$ a $40^{\circ} \mathrm{C}$. Após nova filtragem, o solvente foi removido utilizando evaporador rotativo (Fisatom) sob pressão reduzida (-550) e temperatura controlada $\left(40^{\circ} \mathrm{C}\right)$; em seguida foram levados para capela de exaustão por $24 \mathrm{~h}$ para remoção do excesso do solvente. As frações foram obtidas através do fracionamento por partição líquido-líquido.

Para realizar os testes de germinação utilizou-se as instruções do RAS (BRASIL, 2009) para a espécie, utilizando-se Substrato Sobre Papel, Temperatura $25^{\circ} \mathrm{C}$, com $1^{\mathrm{a}}$ contagem no $2^{\circ}$ dia e contagem final no $10^{\circ}$ dia. Para a medição da radícula e hipocótilo foi utilizado papel milimetrado. Os extratos foram solubilizados em água a uma concentração de $5 \mathrm{mg} / \mathrm{mL}$. Para isso foi realizado experimento composto por sete tratamentos: (água), Tween + DMSO, fração diclorometano, fração hexano, fração acetato de etila e extrato etanólico bruto da parte aérea de Eplingiella fruticosa (Salzm. ex. Benth.) J.F.B. Pastore, na concentração de 5\%. O delineamento foi o DIC (delineamento inteiramente casualizados) com 7 tratamentos e quatro repetições. Os dados foram submetidos a análise de variância, utilizando o teste Tukey a 5\% de probabilidade no programa ${ }^{\circledR}$ statistica versão 8.0.

\section{RESULTADOS E DISCURSSÕES}

O índice de frequência relativa de germinação demonstrou que as sementes submetidas aos controles com Tween + DMSO, com água, herbicida e a fração Hexano apresentaram um pico de germinação entre o $1^{\circ}$ e o $4^{\circ}$ dia, enquanto que as submetidas aos tratamentos contendo acetato de etila, diclorometano e extrato bruto demonstram um pico entre o $3^{\circ}$ e o $5^{\circ}$ dia (Figura 1), o que sugere um retardo na germinação. Os resultados para frequência acumulada demonstraram que o acúmulo da germinação foi entre o $1^{\circ}$ e $4^{\circ}$ dia para os tratamentos: Tween e DMSO, controle água, herbicida e da fração Hexano enquanto os tratamentos contendo acetato de etila, diclorometano e extrato bruto apresentaram uma redução na frequência acumulada (Figura 2). 


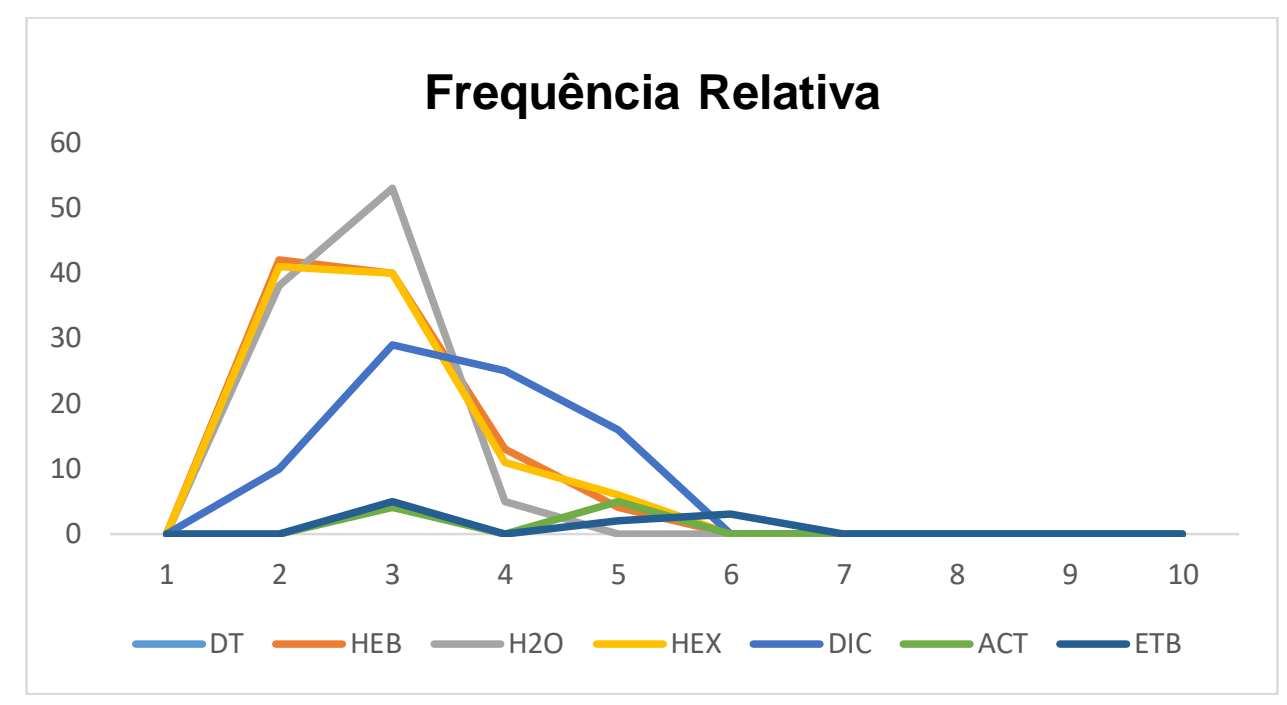

Figura 1. Frequência relativa de germinação de sementes de pepino (Cucumis sativum L) nos diferentes tratamentos. Sendo DT ( Tween + DMSO), HEB (herbicida), H2O (água), HEX (fração hexano), DIC (Fração diclometano), ACT( acetato de etila) e ETB ( extrato bruto) obtido de folhas de Eplingiella fruticosa (Salzm. ex. Benth.) Harley \& J.F.B. Pastore.

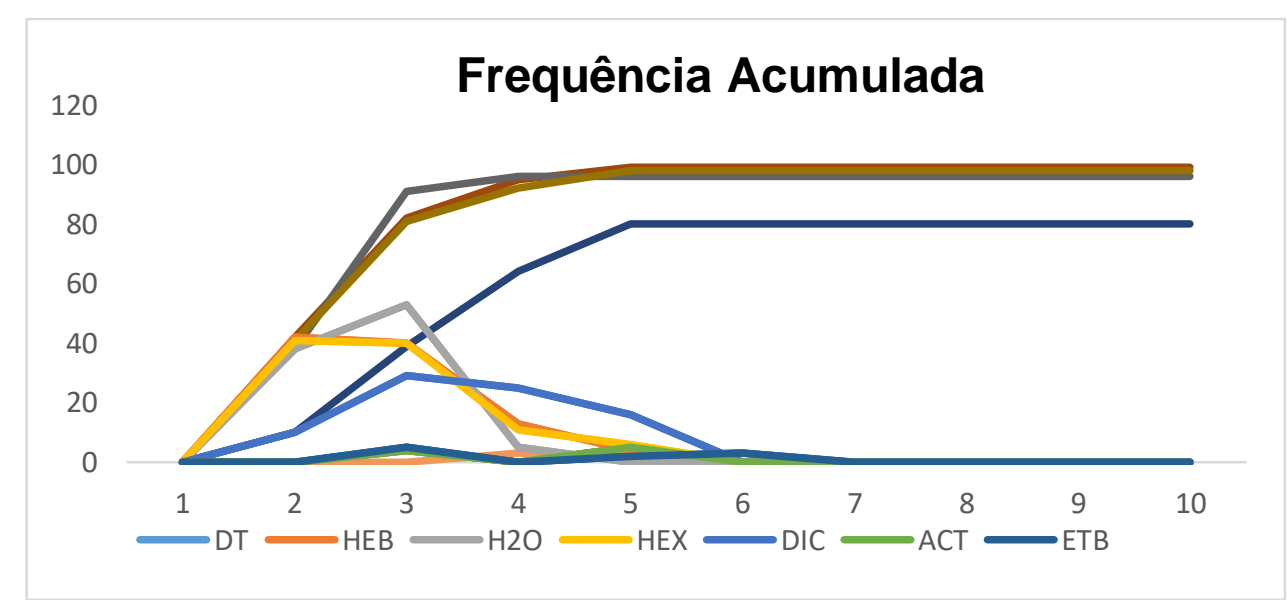

Figura 2. Frequência relativa acumulada de germinação de sementes de pepino (Cucumis sativum L) nos diferentes tratamentos. Sendo DT ( Tween + DMSO), HEB (herbicida), H2O (água), HEX (fração hexano), DIC (Fração diclometano), ACT( acetato de etila) e ETB ( extrato bruto) obtido de folhas de Eplingiella fruticosa (Salzm. ex. Benth.) Harley \& J.F.B. Pastore.

Para o crescimento foi observado uma inibição acentuada no tamanho do hipocótilo e da radícula de pepino, quando as sementes foram submetidas aos tratamentos com as frações acetato de etila, diclorometano e ao extrato bruto, onde as poucas sementes que germinaram apresentaram necrose, o que impediu de se avaliar o tamanho das partes das plântulas. Após o quinto dia do experimento, observou-se que somente as plântulas cujas sementes germinaram 
nos controles com água e DMSO+Tween80 e na fração hexano apresentaram estruturas normais, porém, algumas plântulas crescidas nessa fração apresentaram germinação anormal, com perda da clorofila (Figura 3).

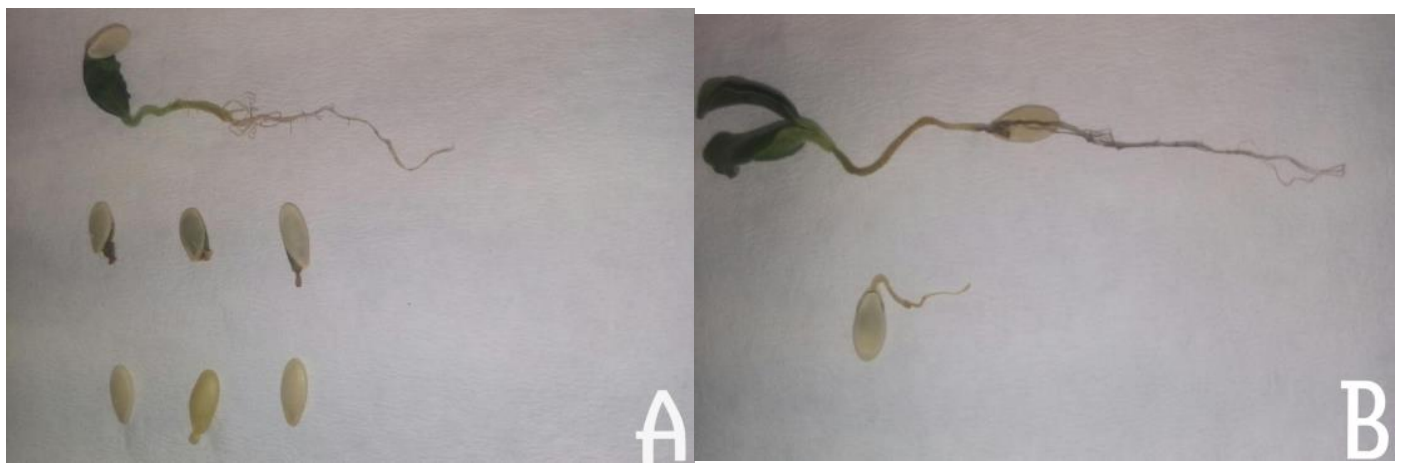

Figura 3. Plântulas de pepino (Cucumis sativum L) germinadas em presença do herbicida, extrato bruto, e Tween + DMSO (A), da fração Hexano e água (B) obtidas de folhas de Eplingiella fruticosa (Salzm. ex. Benth.) J.F.B. Pastore. Feira de Santana, BA, 2019.

Resultados semelhantes foram encontrados no trabalho de OLIVEIRA et.al (2011), onde se observou uma inibição significativa da germinação de sementes Sorghum bicolor L. (sorgo, monocotiledônea), Cucumis sativus L. (pepino, dicotiledônea) e da planta daninha Bidens pilosa L. (picão preto, dicotiledonea) induzida pelo extrato aquoso das folhas de Emilia sonchifolia (Asteraceae).

\section{CONSIDERAÇÕES FINAIS}

O extrato bruto e as frações diclorometano e acetato de etila de E. fruticosa demonstraram efeito alelopático sobre a germinação de semente de Cucumis sativus L., retardando início da germinação, assim como promovendo alterações morfológicas nas plântulas. Os resultados sugerem um real potencial da espécie para o desenvolvimento de herbicidas naturais.

\section{REFERÊNCIAS}

BRASIL. Ministério da Agricultura, Pecuária e Abastecimento. Regras para análise de sementes / Ministério da Agricultura, Pecuária e Abastecimento. Secretaria de Defesa Agropecuária. - Brasília : Mapa/ACS, 2009. 399 p.

OLIVEIRA G. L, BELINELO J, ALMEIDA DE S.M, AGUILAR DE B.E, SFILHO V.G.S. alelopatia de Emiliasonchifolia (l.)Dc. (asteraceae) na germinação e crescimento inicial de sorgo, pepino e picão preto. ENCICLOPÉDIA BIOSFERA, Centro Científico Conhecer - Goiânia, vol.7, N.12; 2011 Pág. 7. 